RASĀYAN J. Chem.

Vol. 13 | No. 4 |2588-2594| October - December | 2020 ISSN: 0974-1496 | e-ISSN: 0976-0083 | CODEN: RJCABP

RJC http://www.rasayanjournal.com http://www.rasayanjournal.co.in

\title{
In-silico MOLECULAR DOCKING ANALYSIS OF ANDROGRAPHOLIDE DERIVED FROM Andrographis paniculata AS POTENTIAL ANTI-HIV AGENT TARGETING HIV-1 REVERSE TRANSCRIPTASE
}

\author{
G. Swapna, D. Rakesh and M. Estari* \\ Department of Zoology, Kakatiya University, Warangal-506009 (Telangana) India \\ *E-mail: drestari@kakatiya.ac.in
}

\begin{abstract}
AIDS (Acquired immunodeficiency syndrome) is a life hostile infection of the humanoid immune structure triggered by HIV (human immunodeficiency virus). Operative inhibition of RT (reverse transcriptase) action is a noticeable clinically feasible tactic for the handling of AIDS. To improve therapeutic choices in contradiction of AIDS we examined novel herbal composite Andrographolide derived from Andrographis paniculata identified to have notable antiviral efficacy. Our docking studies recognized such herbal novel molecule Andrographolide that can bind HIV1RT with great attraction to basis non-competitive inhibition. Consequences are also matched with US FDA approved medicine Nevirapine. Docking study proposes that the ligand Andrographolide has solid binding interfaces with Tyr181, Tyr188, Trp229, Leu100, Val179, Tyr318, Lys101, Pro236, Val106 and Leu234 amino acids, which be appropriate to one or other catalytic pockets of HIV-1 reverse transcriptase. Predictably, these interfaces could be serious in the inhibitory action of the HIV-1 RT. Hence, this study delivers an indication for deliberation of Andrographolide as an appreciated accepted molecule in the managing and prevention of HIV-opportunistic infections.
\end{abstract}

Keywords: AIDS, HIV-1 RT, Molecular Docking, Andrographolide, Nevirapine.

(C) RASĀYAN. All rights reserved

\section{INTRODUCTION}

Andrographis paniculata, inborn to Taiwan, China and India, is a healing herb with an enormously bitter taste used to treat liver complaints, common cold, bowel objections of kids, greater respiratory tract infection and colic pain. ${ }^{1-3}$ The aerial part of $A$. paniculata is usually used in Chinese medication. Rendering to the Chinese medicine concept, A. paniculata relieves internal heat, cools, swelling and pain and is used for detoxification..$^{4-6}$ The herb contains polyphenols, flavonoids and di-terpenoids as the key bioactive phytochemicals. ${ }^{7,8}$ The active constituents of $A$. paniculata are very bitter diterpene lactones known as Andrographolides (APs) ${ }^{9}$ and are the main one in terms of bioactive possessions and profusion. It shows various pharmacological possessions such as immune-stimulatory, anti-viral, anti-inflammatory, anti-platelet aggregation, anti-microbial and hepatoprotective. ${ }^{10}$

The HIV prevalent has the adversely compressed legal, communal and financial status of the previous inhabitants of the universe. As per WHO estimation, almost twenty-five million individuals have pass away owing to this infectious disease. ${ }^{11}$ Rendering to UNAIDS/WHO Report (2019), a whole of forty million individuals of all eternities and sexes harbor HIV world-wide. The HIV-1 RT is a vital player in the life cycle of HIV and an effective target for anti-HIV medicines. ${ }^{12}$ The inhibition of HIV-1 reverse transcriptase is one of the main approaches in the management of AIDS, since this enzyme ${ }^{13-15}$ is accountable for the alteration of the viral RNA (single strand) genome into DNA (double-stranded) that gets later linked into the host genome. ${ }^{16}$ Some inhibitors of HIV-1 RT, like Nevirapine, Rilpivirine and Efavirenz are accessible for the characteristic management of patients with slight to reasonable HIV complications. However, over the years, the utmost of these pharmacophores have been described to yield adversative special effects including liver toxicity, skin rashes and drug allergy. ${ }^{17}$ Natural yields have been and remain to be outstanding sources of therapeutic agents, as templates for synthetic agents ${ }^{18}$. In

Rasayan J. Chem., 13(4), 2588-2594(2020)

http://dx.doi.org/10.31788/ RJC.2020.1345889

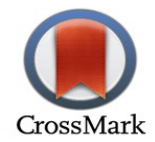


RASĀYAN J. Chem.

Vol. 13 | No. 4 |2588-2594| October - December | 2020

this study, we have recognized Andrographolide (CID: 5318517), a derivative of Andrographis paniculata, as a possible herbal drug candidate mostly against HIV-1 reverse transcriptase. The attained consequences have also been matched with that of the US FDA accepted medicine used for AIDS management and anticipation.

\section{Protein Selection and Preparation}

\section{EXPERIMENTAL}

HIV-1 RT (PDB ID: 3V91) PDB structure was retrieved from Protein Data Bank (RCSB). ${ }^{18}$ Swiss-Pdb viewer v4.1 was used to perform the minimization of energy and to implement stereo-chemical eminence checks to arrive at the best probable three dimensional (3D) HIV-1 RT structure (Fig.-1). ${ }^{19}$ According to the structural possessions and electrostatic of the dynamic and active site of HIV-1 reverse transcriptase, the molecular alignment was done. For accurate ionization and tautomeric positions of amino acid residues, the polar $\mathrm{H}$-atoms were added to the target enzyme or protein. To well understand these interactions, the steric, electrostatic fields and fields of hydrophobic were also mapped against the HIV-1 RT active binding pocket. Molecular docking using HIV-1 RT against selected ligand was completed by 3D structures energy minimization and by adding of the charges.

\section{Ligand Preparation}

Andrographolide (CID: 5318517) and control drug Nevirapine (CID: 4463) of SDF files were retrieved from the NCBI-PubChem database ${ }^{20,21}$ in three dimensional (3D) optimizations (Fig.-2). The PDB coordinate files converted from the SDF structures of these two ligands using Open Babel 2.3.3. ${ }^{22}$ Added kollman united charge to protein and ligands, respectively.

The altered HIV-1 RT 3D structure and ligands responsible for the compatibility of its bonds were changed to the format of PDBQT as mandatory in Auto Dock intentions. In docking, five million energy evaluations and a 150 dockings size of the population with (LGA) Lamarckian Genetic Algorithm were used $^{23}$. Based on RMSD (root mean square deviation) values and uppermost correlation coefficient attained from Auto Dock, the best pharmacophore was designated.

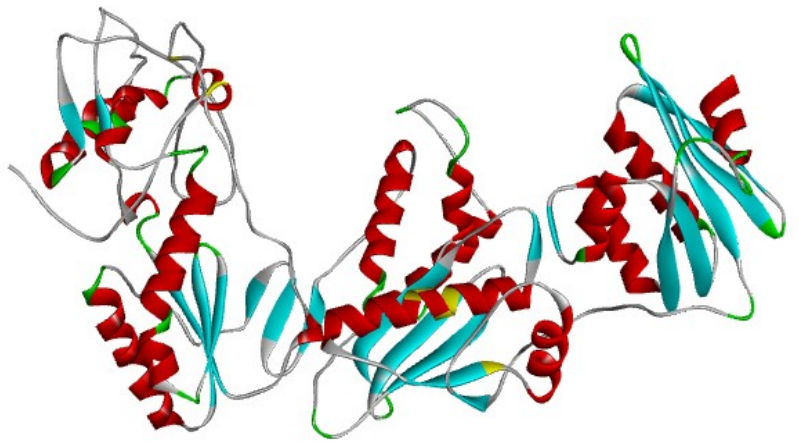

Fig-1: HIV-1 RT 3D Structure (PDB ID: 3V91)

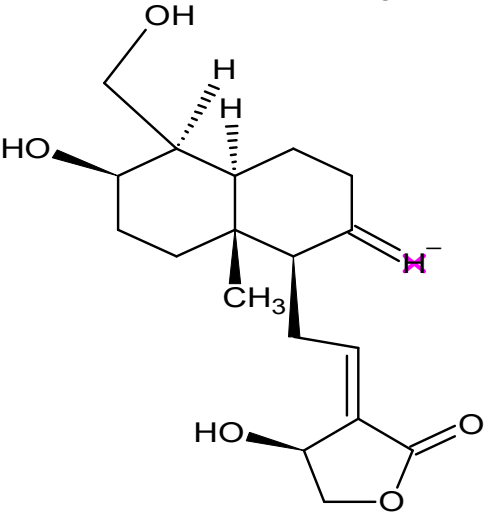

(a)

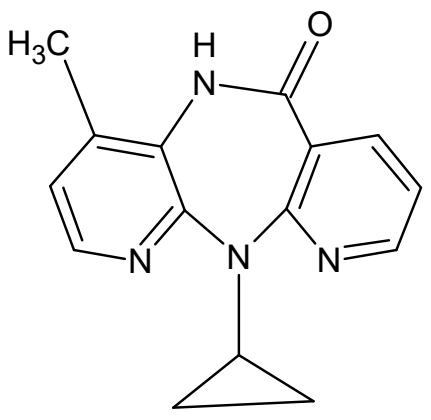

(b)

Fig-2: Molecular Structures of (a) Andrographolide and (b) Nevirapine 
RASĀYAN J. Chem.

Vol. 13 | No. 4 |2588-2594| October - December | 2020

\section{Molecular Docking Using Auto Dock}

To examine the docking simulations, Auto Dock Tools remained used. ${ }^{24}$ Auto Dock 4.2 is recycled to study the molecular connections between the phytochemical ligand Andrographolide and FDA approved drug Nevirapine (reference drug) with the enzyme HIV-1 reverse transcriptase.

Auto Dock needs pre-calculated maps of grids, one for each kind of existing atom in the flexible molecules being docked and it stocks the potential energy rising from the interface with rigid macromolecules. This grid must surround the area of concern in the rigid macro-molecule. Auto Grid 4.2 Program, supplied with Auto Dock 4.2 was used to yield grid maps. The grid size for requiring the exploration space was set to $76,88,104 \mathrm{~A}(\mathrm{x}, \mathrm{y}$, and $\mathrm{z})$ to include all the amino acid moieties which are present in inflexible macro-molecules. The spacing among grid points was 0.972 angstroms. Using AutoGrid 4.0, grid maps are pre-calculated, which normal grids of energy initiated on the contact of the ligand atom analyses with a target of the receptor, were attained. The size of the population was set to 150 and the entities were primed randomly. The extreme number of energy calculations was set to five lakhs, the extreme generation numbers are 27000 .

The docking results were evaluated by reading the binding energy of the docked structure and its interactions. It was run numerous times to get several docked structures and to examine expected docking energy. Based on the lowermost energy and parameterized in terms of docking score in $\mathrm{kcal} / \mathrm{mol}$, the best receptor-ligand structure as of the docked complex was designated. Using the Discovery Studio tool (Version 3.5) the docking consequences were visualized.

\section{Molecular Docking Studies of Andrographolide}

\section{RESULTS AND DISCUSSION}

Over the earlier era, molecular docking consumes and has been established into a technique of prospective practice in computational and therapeutic chemistry and it workings well in expecting chosen locations of contact structure of the bound ligand against receptor. ${ }^{25,26}$ The information of chosen orientation in chance utilizing to estimate the binding affinity strength among the molecules using the scoring purposes. Previous studies have shown that more than thirty diverse classes of NN-RTIs have some different structures i.e., the complete structure might be measured suggestive with hydrophilic interaction epicenter. ${ }^{27}$ The expectation of interactions among lesser molecules and enzymes is a critical step to decode natural procedures and shows a precarious part in medicine find. A hollow nearby the HIV-1 RT dynamic site was expected and mapped on it. The Andrographolide compound having the least binding energy to make a composite with target enzyme in quest for HIV-1 RT potential inhibitors (Table-1) and graded consequently.

Table-1. Characteristics of Andrographolide (CID: 5318517) and Reference Drug Nevirapine (CID;4463) with HIV-1 RT (3V91) after Molecular Docking

\begin{tabular}{|c|c|c|c|c|c|}
\hline $\begin{array}{l}\text { Name of the } \\
\text { Compound }\end{array}$ & $\begin{array}{l}\text { Binding } \\
\text { Energy } \\
\text { (Kcal/ } \\
\text { Mol) } \\
\end{array}$ & $\begin{array}{c}\text { MW } \\
(\mathrm{g} / \mathrm{mol})\end{array}$ & $\begin{array}{l}\text { No. of H-bond } \\
\text { Interaction }\end{array}$ & $\begin{array}{c}\text { Estimated } \\
\text { Inhibition } \\
\text { Constant } \\
(\mathrm{Ki}) \mu \mathrm{m} \\
\end{array}$ & $\begin{array}{c}\text { Intermolecular } \\
\text { Interaction } \\
\text { Energy } \\
\text { (Kcal/Mol) } \\
\end{array}$ \\
\hline $\begin{array}{l}\text { Andrographolid } \\
\text { e } \\
\text { (CID: } 5318517 \text { ) }\end{array}$ & -12.50 & $\begin{array}{c}350.455 \\
\mathrm{~g} / \mathrm{mol}\end{array}$ & $\begin{array}{c}9 \text { (Tyr181, Tyr188, } \\
\text { Trp229, Leu100, Val179, } \\
\text { Tyr318, Lys 101, Pro236, } \\
\text { Val106, Leu234) }\end{array}$ & 682.90PM & -13.69 \\
\hline $\begin{array}{l}\text { Nevirapine } \\
\text { (CID: } 4463 \text { ) }\end{array}$ & -6.08 & $\begin{array}{l}266.3 \\
\mathrm{~g} / \mathrm{mol}\end{array}$ & $\begin{array}{c}\text { 6(Leu234, Pro236, } \\
\text { Val106, Tyr318, Lys101, } \\
\text { Val179, Lys103, Tyr188, } \\
\text { Leu100, Trp229, Tyr181) }\end{array}$ & $34.66 \mu \mathrm{M}$ & -6.95 \\
\hline
\end{tabular}

The interactions of $\mathrm{H}_{2}$ bonds between HIV-1 RT and Andrographolide was envisioned as Fig.-3. Table-1 denotes the docking dynamism and involved amino acid in the interaction of HIV-1 RT with Andrographolide. This study shows that this docking interactive complex is stabilized by the 9 hydrogen bonds with the residues Tyr181, Tyr188, Trp229, Leu100, Val179, Tyr318, Lys101, Pro236, Val106 and 
RASĀYAN J. Chem.

Vol. 13 | No. 4 |2588-2594| October - December | 2020

Leu234 of HIV-1 RT with binding energy $-12.5 \mathrm{Kcal} / \mathrm{Mol}$. The interactions that show a substantial role in the resolve of binding energy and constancy of these receptor-ligand interactive complexes were predictable as bonds of hydrogens.

The interactions of docked Nevriapine with HIV-1 RT enzyme was illustrated in Fig.-4. The docking score of Andrographolide was compared with FDA approved HIV-1 RT inhibitor Nevirapine. The amino acids existing in the active site of HIV-1 RT that interacts with Nevirapine are found to be Leu234, Pro236, Val106, Tyr318, Lys101, Val179, Lys103, Tyr188, Leu100, Trp229 and Tyr181. The docking energy for Nevirapine with HIV-1 RT was considered computationally and establish to be -6.05 $\mathrm{Kcal} / \mathrm{Mol}$. The binding energy of Nevirapine is higher than the Andrographolide states that the Andrographolide is more potent than Nevirapine.

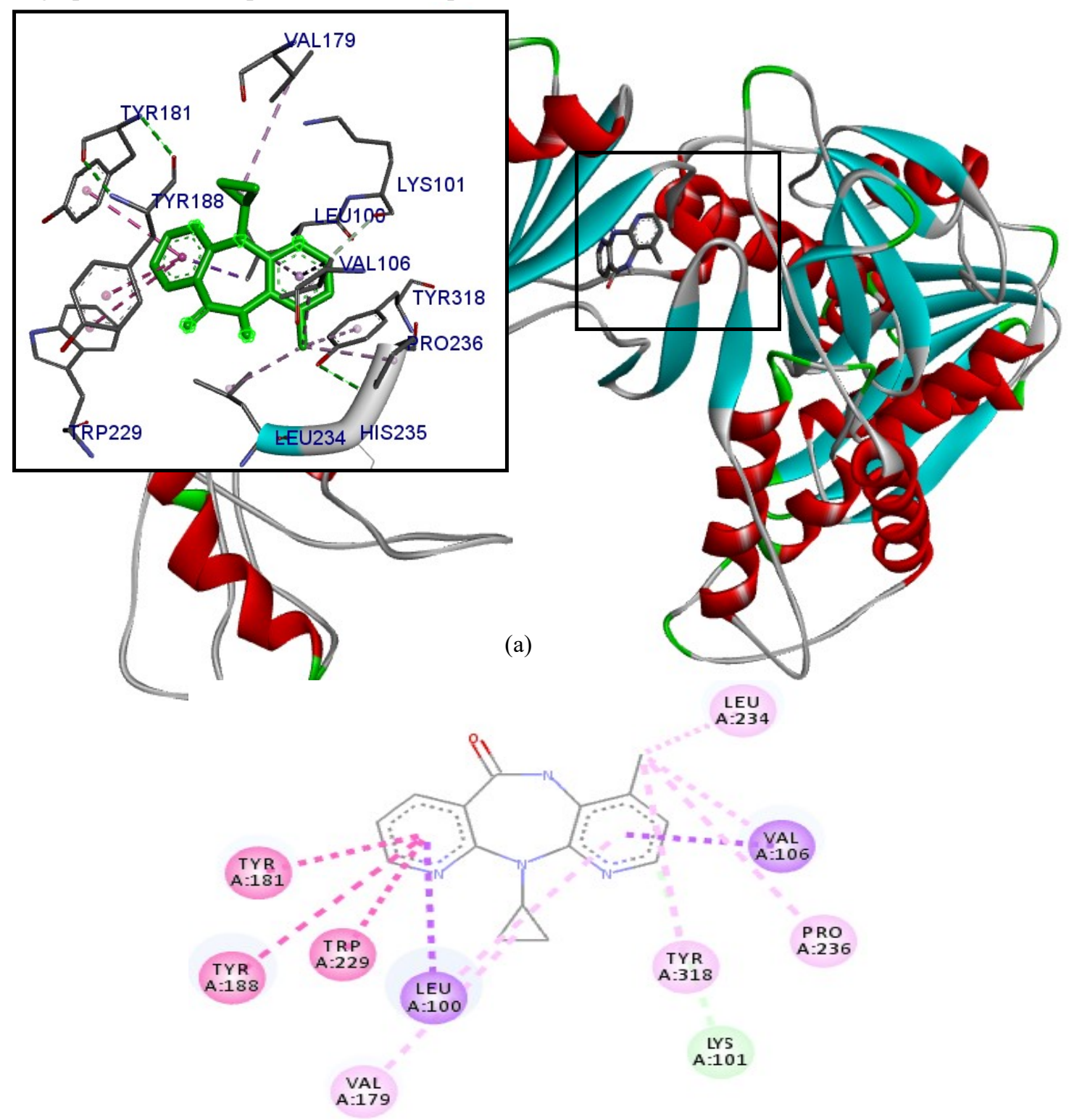

(b)

Fig.-3: Docked Poses of Andrographolide with HIV-1 RT Enzyme.

(a) Cartoon Representation of Docked Complex with the HIV-1 RT Polar Catalytic Traid Residues, and (b) 2D Representation of Docked Complex-forming H-Bonds, Electrostatic and Vander Waals Connections with HIV-1 RT Residues. 
RASĀYAN J. Chem.

Vol. 13 | No. 4 |2588-2594| October - December | 2020
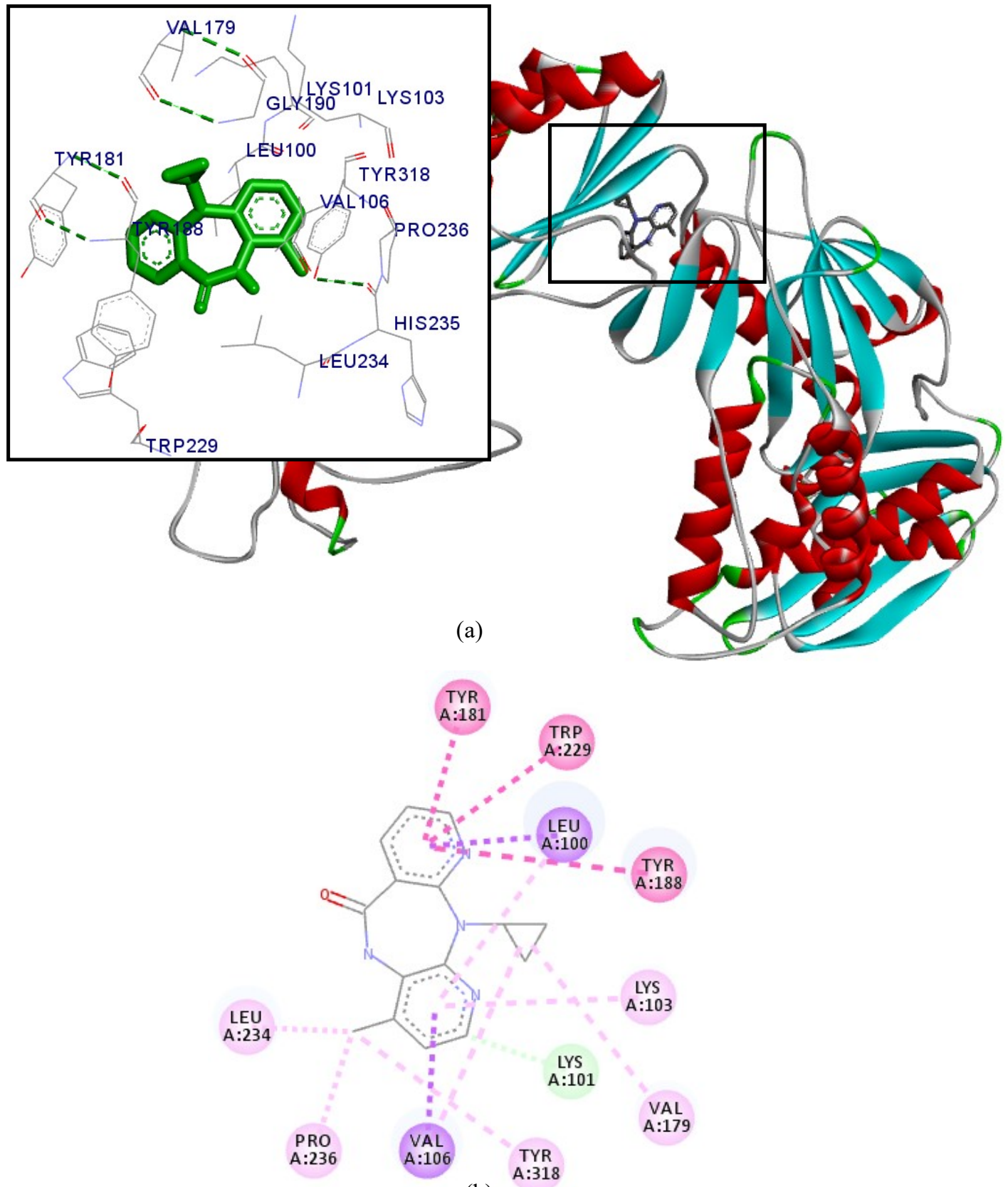

(b)

Fig.-4: Interactions of Nevirapine with HIV-1 RT enzyme.

(a) Cartoon representation of Nevirapine relating with the HIV-1 RT polar catalytic residues, and (b) 2D representation of docked Nevirapine establishing H-bonds, electrostatic and Van der Waals connections with HIV-1 RT residues.

Apart from hydrogen bonds, Andrographolide was also initiated involved in widespread hydrophobic Van der Waal connections as shown in Fig.-1A, with Leu100, Val106, Tyr181, Tyr188, Trp229 and Val179 of catalytic subside amino acid residues. We witnessed that Andrographolide have stout inter-molecular and intra-molecular interactions with HIV-1 RT active amino acid residues that control a range of protein structure containing binding and translocation of the nucleic acid substrate. Based on Complex scoring, connections with the active site of amino acid residue and binding ability it is interpreted that Andrographolide could be a promising HIV-1 RT inhibitor. 
RASĀYAN J. Chem.

Vol. 13 | No. 4 |2588-2594| October - December | 2020

In the current study, the binding appliance of a potential natural compound Andrographolide with HIV-1 RT was illuminated using molecular docking. The ligand-binding pocket of confirmation structure alterations comprising the active catalytic amino acid residues (Tyr181, Tyr188, Trp229, Leu100, Val179, Tyr318, Lys101, Pro236, Val106, Leu234) and other important amino acid motifs have been predictable. Additionally, the docking results propose that ligand interactions with the HIV-1 RT amino acid motifs Val106, Leu100, Tyr181, Trp229, Tyr188 and Val179, all of which fall beneath one or other active binding pockets, could be crucial for HIV inhibition. The current docking study of Andrographolide molecule could be a capable small ligand for the HIV-1 RT inhibition and may act as therapy for the handling of HIV/AIDS infection. These outcomes would be treasured for additional scheming noncovalent inhibitors with great specificity and better strength.

\section{CONCLUSION}

The binding mechanism of a prospective natural phytochemical Andrographolide with HIV-1 RT has been explained by molecular docking in this present study. The confirmation of structural alterations in the ligand-binding pocket containing the catalytic active amino acid residues (Tyr181, Tyr188, Trp229, Leu100, Val179, Tyr318, Lys101, Pro236, Val106, Leu234) and other important motifs have been recognized. Additionally, the docking outcomes suggest that ligand interactions with the residues of HIV1 RT amino acids Val106, Leu100, Tyr181, Tyr188, Val179 and Trp229, all of which drop under one or other dynamic binding pockets, could be precarious for HIV inhibition. The current docking study of Andrographolide molecule, could be a capable lead molecule for the HIV-1 RT inhibition and act as medicine for the management of HIV/AIDS infection. These outcomes would be valued for further planning inhibitors of non-covalent type with higher specificity and more strength.

\section{ACKNOWLEDGEMENT}

All the authors are thankfully acknowledged to the Department of Zoology, Kakatiya University, Warangal district, Telangana State, India for providing a computational facility to carry out this study. No funding to declare.

\section{REFERENCES}

1. A.S. Negi, J.K. Kumar, S. Luqman, K. Sbanker, M.M. Gupta, S.P.S. Kbanuja, Medicinal Research Review, 28(5), 746(2008), DOI:10.1002/med.20115

2. M. Roxas, J. Jurenka, Alternative Medicinal Review, 12(1), 25(2007)

3. B. Kligler, C. Ulbricht, E. Basch, C.D. Kirkwood, T.R. Abrams, M. Miranda, K.P. Singh Khalsa, M. Giles, H. Boon, J. Woods, Explore, 2(1), 25(2006), DOI:10.1016/j.explore.2005.08.008

4. C.J. Huang, M.C. Wu, Journal of Biomedical Science, 9(6), 596(2002), DOI:10.1159/000067288

5. W.W. Chao, Y.H. Kuo, W.C. Li, B.F. Lin, Journal of Ethnopharmacology, 122, 68(2009), DOI: $10.1016 /$ j.jep.2008.11.029

6. S.C. Mandal, A.K. Dhara, B.C. Maiti, Phytotherapy Research, 15(3), 253(2001), DOI: $10.1002 /$ ptr.704

7. Y.K. Rao, G. Vimalamma, C.V. Rao, Y. Tzeng, Phytochemistry, 65(16), 2317(2004), DOI: $10.1016 /$ j.phytochem.2004.05.008

8. C. $\mathrm{Xu}, \mathrm{GX}$, Chou, ZT, Wang, Phytochemistry, 77, 275(2012), DOI: $10.1016 /$ j.phytochem.2011.12.020

9. G.A. Akowuah, I. Zhari, I. Norhayati, A. Mariam, Journal of Food Composition and Analysis, 19(23), 118(2006), DOI:10.1016/j.jfca.2005.04.007

10. K.R. Ajaya, K. Sridevi, K.N. Vijaya, S. Nanduri, S. Rajagopal, Journal of Ethnopharmacology, 92(23), 291(2004), DOI:10.1016/j.jep.2004.03.004

11. T. Ren-rong, L. Qingjiao, and C. Xulin, Virologica Sinica, 22, 476(2007), DOI:10.1007/s12250-0070049-5

12. L. Hopkins, J. Ren, R. M. Esnouf, B. E. Willcox, E. Y. Jones, C. Ross, T. Miyasaka, R. T. Walker, H. Tanaka, D. K. Stammers, and D. I. Stuart, Journal of Medicinal Chemistry, 39(8), 1589(1996), DOI: $10.1021 / \mathrm{jm} 960056 \mathrm{x} 8648598$ 
RASĀYAN J. Chem.

Vol. 13 | No. 4 |2588-2594| October - December | 2020

13. E. De Clercq, International Journal of Biochemistry and Cell Biology, 36(9), 1800(2004), DOI: 10.1016/j.biocel.2004.02.015

14. G. Sarafianos, K. Das, C. Tantillo, A. D. Clark Jr., J. Ding, J. M. Whitcomb, P. L. Boyer, S. H. Hughes, and E. Arnold, EMBO Journal, 20(6), 1449(2001), DOI:10.1093/emboj/20.6.1449

15. K.P. Solankee, Patel, and R. B. Patel, Archives of Applied Science Research, 4, 72(2012), DOI: $10.1109 /$ TCBB.2015.2415771

16. Jacobo-Molina and E. Arnold, Biochemistry, 30(26), 6351(1991), DOI:10.1021/bi00240a001

17. R. Purohit and R. Sethumadhavan, Interdisciplinary Sciences, 1, 320(2009), DOI: $10.4172 /$ jcsb. 1000062

18. R. Purohit, V. Rajendran, and R. Sethumadhavan, Journal of Biomolecular Structural Division, 29(1), 137(2011), DOI:10.1080/07391102.2011.10507379

19. https://www.rcsb.org/structure/3V91

20. R. Purohit, Journal of Biomolecular Structure and Dynamics, 32, 1033(2014), DOI: $10.1080 / 07391102.2013 .803264$

21. https://pubchem.ncbi.nlm.nih.gov/compound/5318517

22. https://pubchem.ncbi.nlm.nih.gov/compound/4463

23. J. Dundas, Z. Ouyang, J. Tseng, A. Binkowski, Y. Turpaz, and J. Liang, Nucleic Acids Research, 34, 116(2006), DOI: 10.1093/nar/gk1282

24. G. P. Brady Jr. and P. F. Stouten, Journal of Computer-Aided Molecular Design, 14, 383 (2000), DOI: $10.1023 / \mathrm{A}: 1008124202956$

25. O. Trott, A.J. Olson, Journal of Computational Chemistry, 31(2), 455(2010), DOI:10.1002/jcc.21334

26. G. M. Morris, R. Huey, W. Lindstrom, M. F. Sanner, R. K. Belew, D. S. Goodsell, and A. J. Olson, Journal of Computational Chemistry, 30(16), 2785(2009), DOI: 10.1002/jcc.21256

27. http://www.pymol.org

28. A. Gupta, P. Gandhimathi, Sharma, and B. Jayaram, Protein and Peptide Letters, 14(7), 632(2007), DOI: $10.2174 / 092986607781483831$

[RJC-5889/2020] 